\title{
Impact of population growth and climate change on the resilience of Florina's hydrosystem
}

\author{
ELISSAVET FELONI and EVANGELOS BALTAS \\ Department of Water Resources and Environmental Engineering, School of \\ Civil Engineering, National Technical University of Athens Heroon \\ Polytechniou 9, Zografou, 15780 Athens \\ GREECE
}

\begin{abstract}
This research work deals with an integrated assessment regarding a hydrosystem's resilience under changing conditions. Particularly, the analysis is performed for Florina, a rural area in Northern Greece. In Florina, four reservoirs operate to meet water requirements for agriculture and industrial use, as well as, to satisfy the urban water demand of the local population. The analysis initially includes the hydrologic simulation of the natural system that is achieved by developing and implementing a hydrologic model on a monthly basis, using the available historic data for the region. It also incorporates the development of the reservoirs' monthly water balance models to assess the reliability of the system based on the current water requirements and the historic datasets. In terms of rational water resources management under changing conditions, various combinations are investigated; all of which are based on four main scenarios (i.e., zero, three climate change scenarios, population growth scenario, scenarios regarding different distribution of irrigation water). The comparison among the aforementioned scenarios is finally shown through the variation in the hydrosystem's reliability to meet water demands. Results show that each reservoir presents its own behavior with respect to its particular technical characteristics and the scenario performed. In general, reliability decreases, while, the implementation of the scenarios that introduce different practices regarding water distribution for irrigation showed that this practice can ensure a relatively higher reliability to the local hydrosystem.
\end{abstract}

Key-Words: water resources management; hydrosystem; reservoir; water demand; climate change; Florina

Received: September 18, 2019. Revised: February 1, 2020. Accepted: February 11, 2020. Published: February 19, 2020.

\section{Introduction}

Rational planning and management of water resources is a very complex and difficult task under the best of circumstances [1]. Over the years, the effects of climate change in combination with the positive growth rate of population are expected to have a significant impact on water resources and, as such, a current estimate of the available resources is necessary for performing future projections and implement the necessary water management plans. In order to evaluate the available resources, hydrologists use hydrological models to simulate both the physical processes at a watershed level and the operation of hydrosystems. The daily and monthly time step water balance models are primary used for the quantification of the stream flow. Nevertheless the uncertainty generated during hydrological analysis is significant and the success depends on various factors, such as the available data and the basin's characteristics [2].

The objective of this study is to perform an integrated analysis regarding Florina's hydrosystem resilience under changing climatic conditions and population growth. To evaluate the current state of water resources, a hydrologic simulation is performed on a monthly basis and at a watershed level to finally assess the input parameters for the monthly reservoir simulation. Due to the streamflow data scarcity in the region, the analysis is based on the implementation of the "abcd" monthly water balance model [3, 4], considering the model parameters proposed by Bournas et al. [2] for the same region. Four reservoir models are also developed, taking into account the specific technical characteristics and restrictions of each dam. The integrated watershedreservoir monthly water balance model is initially performed for a zero scenario, that is based on the available historic data and 
represents the current state regarding water resources management (WRM) practices, in terms of water requirements and water supply distribution. Afterwards, additional scenarios are investigated, based on four main scenarios; the zero, three climate change scenarios, population growth scenario and scenarios regarding different distribution of irrigation water. The comparison among the aforementioned scenarios is performed in terms of percentage reduction of the system's reliability to meet water demand. Results show that each reservoir presents its own behavior with respect to their particular technical characteristics and the scenario performed. In general, reliability decreases in all examined scenarios, while the implementation of the scenarios that introduce different practices regarding irrigation water supply distribution showed that this practice can ensure a relatively higher reliability to the local hydrosystem.

The rest of the paper is structured as follows. Section 2 provides the description of study area and data used. In Section 3 the approach regarding hydrologic modeling, reservoir simulation and concept of scenarios is presented. Section 4 includes the results derived from the models and scenarios presented in the previous section, while a brief discussion is also included, and finally, Section 5 concludes the paper.

\section{Study Area and Data Used}

\subsection{Description of the study area}

The Municipality of Florina, located in Northern Greece, is a subbasin of the Axios river catchment, a case of a transboundary river, which expands between Greece and North Macedonia (Fig.1). It is a semi-agricultural region, with a total area of 821.2 $\mathrm{km}^{2}$. From a geomorphological point of view, the region presents rich landscapes, with mountainous, hilly and also lowland character. The mean slope of the region is $10.7^{\circ}$ and the mean elevation is $954 \mathrm{~m}$. The surrounded high mountains of Voras (Kaimaktsalan peak in $2524 \mathrm{~m}$ elevation), Varnountas (Peristeri peak in $2334 \mathrm{~m}$ ), and Vernon (Vitsi peak in $2128 \mathrm{~m}$ ), in combination with a large number of lakes located in the greater region, form the unique climate of Florina characterized by severe winters and an extremely short dry period of 3.5 months. Based on 30 year climatology, the mean annual temperature is about $10.5^{\circ} \mathrm{C}$, whereas, the mean annual precipitation is equal to $662 \mathrm{~mm}$; however, there is a significant variation between the highlands and lowlands annual percentage of rainfall and snow. From a geomorphological point of view, there are several main streams that overflow the region and finally contribute to the main river named Lingos (Axios), and also there are four dams, namely Parorio (about $10 \mathrm{~km}$ from the city of Florina), Triantafillia (about $10 \mathrm{~km}$ from Florina), Kolhiki (about $10 \mathrm{~km}$ from Florina) and Papadia-Skopos (about $30 \mathrm{~km}$ from Florina), as it is presented in Fig.1. The main characteristics of each dam and the corresponding catchment areas are summarized in Table 1.

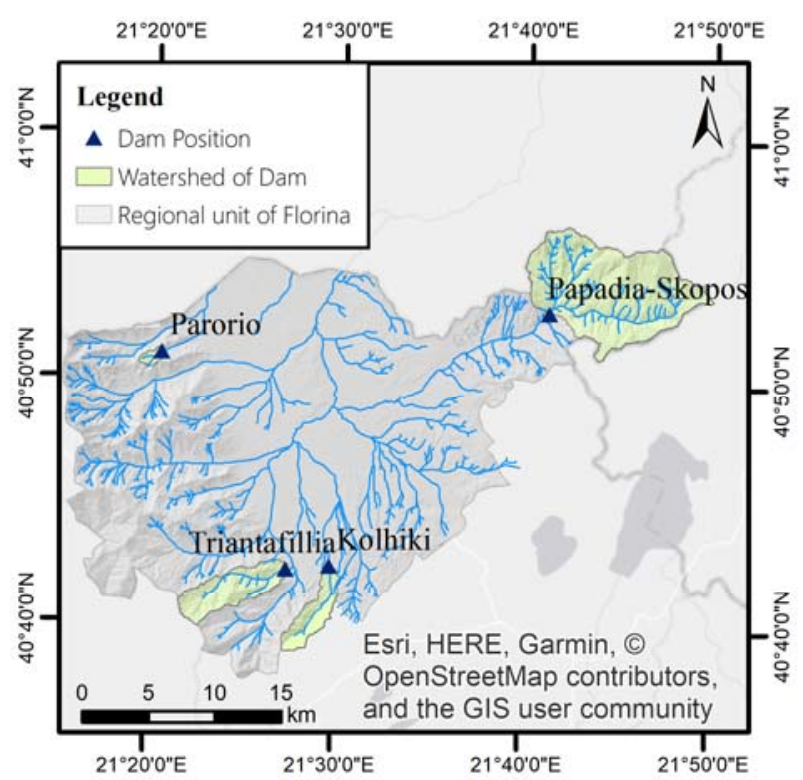

Figure 1. Study area

Kolhiki Dam is located in the southern part of the Municipality of Florina, NE of the village of Ano Idroussa and west of the village of Flambouro. It is located on the torrent upstream of Colhis, which contributes to the Palio Rema about $5 \mathrm{~km}$ downstream of the dam. The total reservoir capacity is $1.2 \cdot 10^{6} \mathrm{~m}^{3}$, with a reservoir area of $137000 \mathrm{~m}^{2}$.

Triantafillia Dam is located on the stream of Asprorema (Triantafillia torrent), between the settlements of Idroussa and Drosopigi, approximately $1.5 \mathrm{~km}$ southwest of the settlement of Kato Idroussa and $10 \mathrm{~km}$ from the city of Florina. It is an earth dam with a central impermeable core and forms the largest reservoir in the area. The main characteristics of the dam are summarized as follows: (i) Total reservoir volume: $10.1 \cdot 10^{6} \mathrm{~m}^{3}$, (ii) Effective reservoir volume: $9.56 \cdot 10^{6} \mathrm{~m}^{3}$, (iii) Maximum reservoir level: $838 \mathrm{~m}$, (iv) Bottom 
reservoir level: $800 \mathrm{~m},(\mathrm{v})$ Guaranteed abstraction: $14.106 \mathrm{~m}^{3} /$ year, (vi) Dam height from substructure: $75 \mathrm{~m}$, (vii) Maximum length: $510 \mathrm{~m}$, (viii) Dam volume: $2.7 \cdot 10^{6} \mathrm{~m}^{3}$, (ix) Dam slope: $2: 1$ (uphill slope) 1.8:1 (downhill slope). Its main purpose is to meet irrigation water requirements $\left(\sim 13 \cdot 10^{6} \mathrm{~m}^{3} /\right.$ year), while further water abstraction of $1.8 \cdot 10^{6}$ $\mathrm{m}^{3} /$ year is also considered to meet the emergency water supply needs of the city of Florina.

Parorio Dam is the newest dam in the area, between the settlements of Kratero and Parorio. Its reservoir capacity is $1.5 \cdot 10^{6} \mathrm{~m}^{3}$ that corresponds to an area of about $0.15 \mathrm{~km}^{2}$. The proposed project aims to irrigate approximately 3000 acres.

Finally, Papadia-Skopos Dam is located near the ruins of the abandoned village of Papadia and includes a water supply pipe up to the local energy production station. Regarding the reservoir characteristics, the maximum operation level is at $928 \mathrm{~m}$ and the minimum at $890 \mathrm{~m}$. The maximum effective capacity is $13 \cdot 10^{6} \mathrm{~m}^{3}$ and corresponds to a surface area of $600 \cdot 10^{3} \mathrm{~m}^{3}$. It is also an earth dam with a central impermeable core, with a mass volume of $3.3 \cdot 10^{3} \mathrm{~m}^{3}$, maximum length $581 \mathrm{~m}$ and maximum altitude (at crown) $933 \mathrm{~m}$. Regarding water storage and abstractions, the volume of stored water is about $13 \cdot 10^{6} \mathrm{~m}^{3}$, for cooling of the energy production station of Melite (5000 operating hours) a quantity of $6.8 \cdot 10^{6} \mathrm{~m}^{3} /$ year is provided with a standard flow of $0.378 \mathrm{~m}^{3} / \mathrm{s}$. A constant ecological flow is also set at $1.2 \cdot 10^{6} \mathrm{~m}^{3} /$ year $\left(0.04 \mathrm{~m}^{3} / \mathrm{s}\right)$. Urban water supply corresponds to $1.0 \cdot 10^{6} \mathrm{~m}^{3} /$ year, while the reservoir provides water for irrigation purposes the period between May and September (about $4 \cdot 10^{6}$ $\left.\mathrm{m}^{3}\right)$.

Table 1. Characteristics of the reservoirs' upper catchment areas

\begin{tabular}{|l|r|r|r|r|}
\hline & Kolhiki & Triantafillia & Parorio & $\begin{array}{c}\text { Papadia } \\
\text { Skopos }\end{array}$ \\
\hline $\begin{array}{l}\text { Maximum } \\
\text { Elevation }\end{array}$ & 1689.02 & 1879.69 & 1129.76 & 2521.84 \\
\hline $\begin{array}{l}\text { Mean } \\
\text { Elevation }\end{array}$ & 1159.86 & 1247.44 & 1018.64 & 1541.41 \\
\hline $\begin{array}{l}\text { Minimum } \\
\text { Elevation }\end{array}$ & 1159.86 & 784.06 & 927.13 & 893.36 \\
\hline $\begin{array}{l}\text { Catchment } \\
\text { area (km }\end{array}$ & 11.20 & 18.90 & 1.56 & 77.00 \\
\hline $\begin{array}{l}\text { Mean } \\
\text { annual } \\
\text { runoff } \\
\text { (hm }^{\mathbf{3}} \text { ) }\end{array}$ & 2.04 & 15.10 & 0.72 & 35.60 \\
\hline
\end{tabular}

\subsection{Datasets and preprocessing}

To perform the hydrologic simulation of the natural system by developing and implementing a hydrologic model on a monthly basis, as well as, to simulate of the reservoirs' system operation, all available historic data regarding monthly timeseries of precipitation and temperature, and daily urban, irrigation and industrial water requirements are taken into consideration. Furthermore, data regarding the reservoirs characteristics, necessary for defining the storage capacity of reservoirs (i.e., area-capacity curves, etc.), are analyzed. Finally, timeseries regarding climatic scenarios are also determined for the region.

Particularly, as the available precipitation and temperature data for the region of Florina are characterized by high heterogeneity and various periods of operation, the EOBS dataset [5] is used, after applying the necessary quality control with respect to the observed timeseries. The EOBS dataset covers the whole land of the European continent and it is the result of the European research project ENSEMBLES and ECA\&D [6]. EOBS dataset was created using a large number of meteorological stations in Europe (including Greece, using the HNMS station data), after a process that involves spatial integration. This data provide the daily information of the rainfall intensity, the surface temperature, as well as, the atmospheric pressure at sea level and it is provided in a spatial resolution of $0.25^{\circ}$ in both directions. For the "abcd" model application, the weighted monthly precipitation and temperature timeseries from the EOBS gridded datasets were calculated, and assumed as the precipitation input for the model and temperature input for the estimation of the evapotranspiration, respectively.

Regarding the four reservoirs' stage-storage capacity and stage-surface area curves, the corresponding values are summarized in Fig.2.

In the framework of this analysis, the interpolation between the available sets of parameters is achieved by applying GIS techniques, using the available digital elevation model of $5 \mathrm{~m}$ spatial resolution for each catchment upstream the corresponding dam. In order to quantify the total demand per reservoir, the aforementioned values are considered in combination with the analysis of available data of daily water consumption per capita that differs among settlements. Using the available dataset of spatial distribution of crops that is provided by the Greek Payment Authority of Common Agricultural Policy (C.A.P.), irrigation water requirements are estimated as distributed and after considering the different requirements of each crop.

The initial simulation both for the runoff estimation and for the reservoirs' model implementation is conducted using a deterministic 
approach as it refers to a historic period of operation (i.e., hydrometeorological datasets and water requirements), for a given storage capacity of each reservoir.

Finally, three climate change (CC) scenarios (of mild, moderate and severe impact) are investigated and, for this reason, the freely available timeseries of the Coordinated Regional Downscaling Experiment (CORDEX; [7]) were utilized. Among the CORDEX objectives is to produce coordinated sets of regional downscaled projections (including through empirical statistical downscaling, ESD) worldwide; to make data sets readily available and useable. Based on the resolution that data are provided in, two grid points (Lon: 21.73189, Lat: 40.83274 and Lon: 21.43887, Lat: 40.73353) are required. The scenarios (combination of regional and global climate model) that are utilized for the period 2020-2050 are shown in Fig.3.

The aforementioned scenarios (Fig.3) were implied in Florina's hydrosystem through the use of a conceptual water balance model, which has been used for the assessment of the regional hydrological effects of climate change.
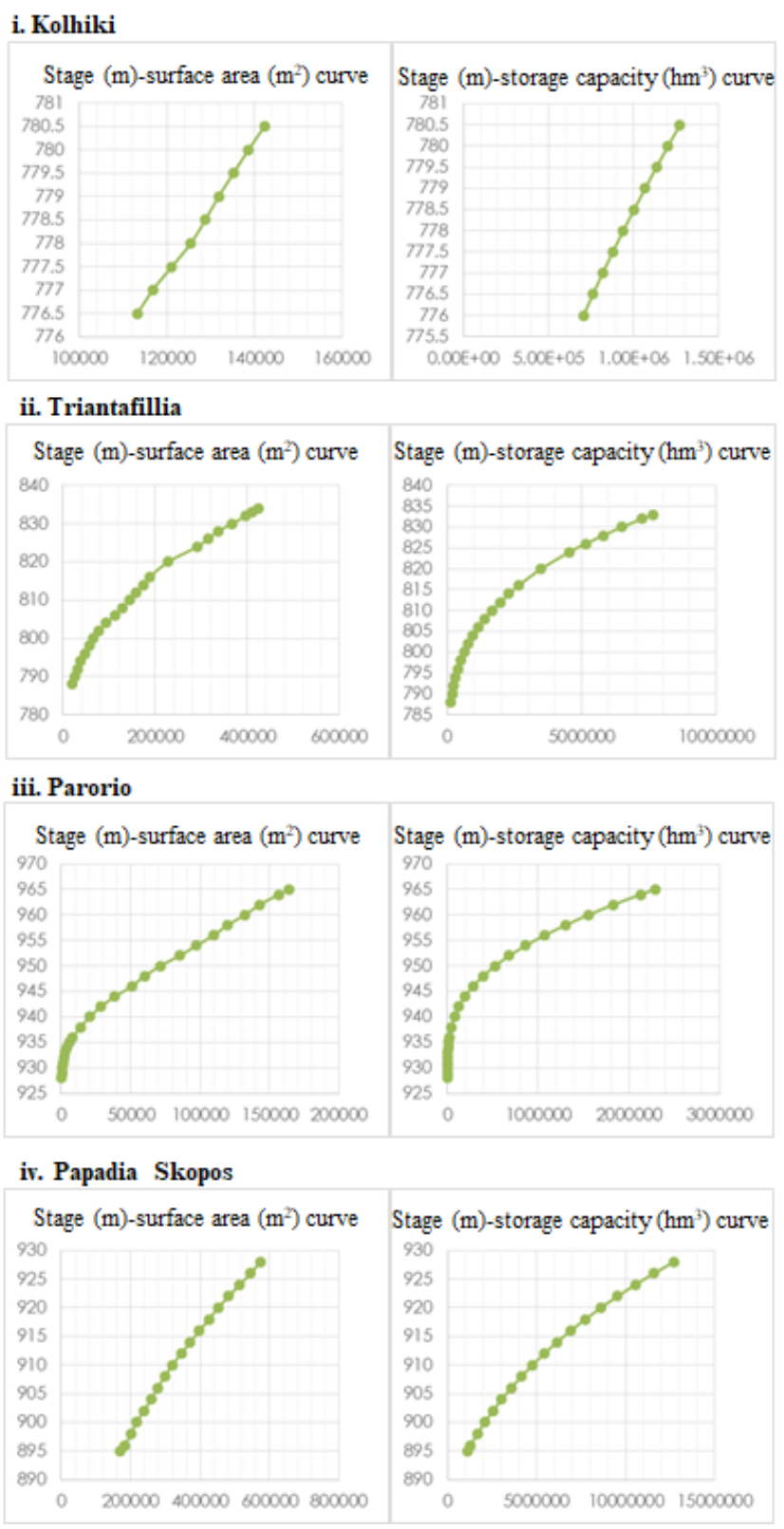

Figure 2. Stage-Surface area and Stage-Storage capacity curves for the four reservoirs 


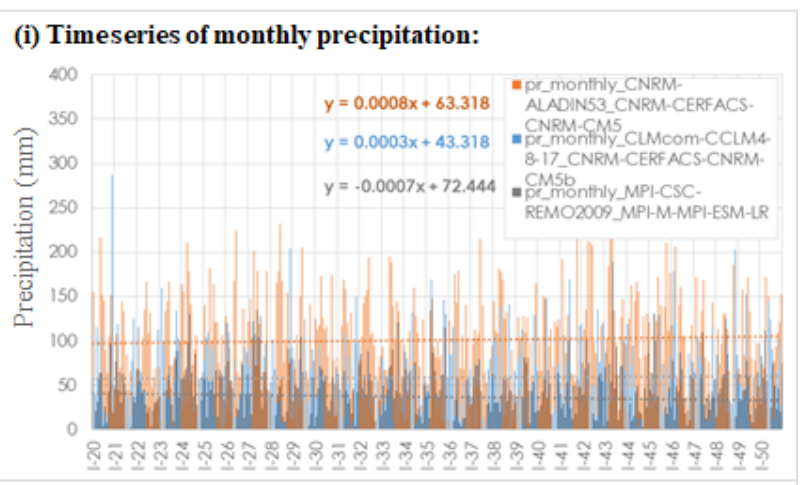

(ii) Timeseries of monthly temperature:

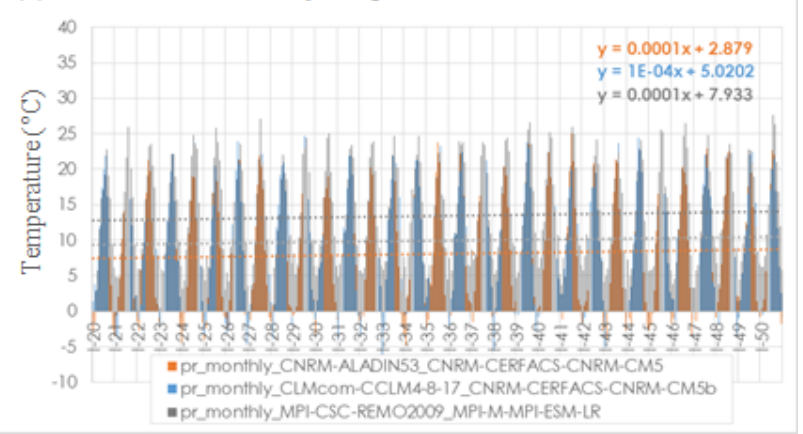

Figure 3. Timeseries of CC scenarios

\section{Methods and scenarios}

\subsection{Model description}

In order to assess the monthly runoff in the entrance of each reservoir, the "abcd" water balance model is developed and implemented, considering different values for the model parameters (i.e., parameters a, b, c, and d), as proposed by Bournas et al. [2]. The "abcd" model is a simple nonlinear conceptual watershed model which accepts precipitation and potential evapotranspiration as input, and produces streamflow and actual evapotranspiration as output [3] and it is schematically comprised of two storage compartments: soil moisture and groundwater. The soil moisture storage (S) receives water from precipitation $(\mathrm{P})$ and loses water through potential evapotranspiration (ET), surface runoff (DR) and groundwater recharge (GR). The groundwater compartment gains water from recharge and loses water as discharges. The total streamflow is the sum of surface runoff from the soil moisture and groundwater discharge. There are four parameters governing the model behavior: 'a' controls the amount of runoff and recharge that occurs when the soil is not saturated; ' $b$ ' controls the saturation level of the soil; 'c' defines the ratio of groundwater recharge to surface runoff; and, finally, parameter ' $d$ ' accounts for the rate of groundwater discharge [8].

The reservoir monthly water balance simulation model is based on the fundamental Equation $1[9,10]$ :

$$
\mathrm{V}_{\mathrm{t}+1}=\mathrm{V}_{\mathrm{t}}+\mathrm{Q}_{\mathrm{obs}, \mathrm{t}}+\mathrm{P}_{\mathrm{t}}-\mathrm{EPT}_{\mathrm{t}}-\mathrm{a}_{\mathrm{i}} \mathrm{W}-\mathrm{N}_{\mathrm{t}}
$$

Where:

$V_{t+1}$ : the stored volume at the end of the month $t$ $V_{t}$ : the stored volume at the beginning of the month $t$

$Q_{o b s, t:}$ the monthly inflow into the reservoir

$P_{t}$ : the monthly precipitation on the surface of the reservoir

$E P T_{t}$ : the monthly evaporation from the surface of the reservoir

$W$ : the outflow

$a_{i}$ : the monthly coefficient for the distribution of W with: $\sum_{i=1}^{12} \alpha_{i}=1$

$N_{t}$ : the uncontrolled monthly losses (spills) from the reservoir.

For the purpose of modeling reservoir losses, the corresponding factor was estimated at $2 \%$ of the stored volume for each time step of the simulation. All variables are estimated for each one of the four reservoirs as a function of the corresponding StageSurface area-Storage capacity curves.

The constraints of the model are those that essentially judge whether the reservoir fails to meet the demand for a month (that is, when the volume tends to fall below the minimum) or whether the water stored in the reservoir overflows. This limitation is set for each reservoir according to Equation 2:

$$
\mathrm{V}_{\min } \leq \mathrm{V}_{\mathrm{t}} \leq \mathrm{V}_{\text {max }}
$$

Where:

$V_{t}$ : the volume stored at the end of the month $t$ $V_{\min }$ : the minimum volume stored in the reservoir

$V_{\max }$ : the maximum volume stored in the reservoir.

\subsection{Scenarios description}

With regard to the scenarios that are investigated, there are four main scenarios (A to D) and 16 combinations among them, as shown in the following Section 4. Each scenario's name is a result of the main coding ( $A$ to $\mathrm{D}$ ) followed by an 
index (1 to 3 ) for the three CC scenarios to finally form the following scenarios:

A: The zero-sum scenario. It corresponds to the original simulation, according to the historical time series available for the area and to the urban, irrigation and, in some cases, industrial water needs that each system is designed to meet.

$B_{1}-B_{2}-B_{3}$ : Climate change scenarios. Three scenarios were selected to investigate, one severe, one moderate and one relatively mild CC scenario. The most severe is the one associated with the highest decrease in precipitation and a simultaneous increase in monthly temperature. It is noteworthy that all scenarios show a slight increase in future rainfall, while the temperature shows a very slight positive trend.

$C$ : Scenario of population growth. The worstcase scenario that increases urban water demand at about $7 \%$ with reference to the year of the last census (2011) up to 2050. The population growth scenario was applied to the historical time series of the zero scenario (scenario $A-C$ ) and to the $C C$ scenarios $\left(B_{1}-C, B_{2}-C, B_{3}-C\right)$.

$D$ : Scenarios for irrigation water distribution. For each of the above scenarios (zero, $\mathrm{CC}$, population) the last one scenario was combined (i.e., $A-D, A-C$ $\left.D, B_{1}-D, B_{2}-D, B_{3}-D, B_{1}-C-D, B_{2}-C-D, B_{3}-C-D\right)$. The final scenarios are considered as an additional means of highlighting the effect of adopting different distributions regarding irrigation water supply on the hydrosystem's reliability.

\section{Results and Discussion}

The model used in this research work is a physically based water balance model that operates on a monthly basis requiring the input variables, which have been defined and discussed above. The model was successfully calibrated using historical hydrometeorological and hydrometric data at Siatista basin by Bournas et al. [2]. The values of model parameters are set as shown in Table 2.

Table 2. Values of 'abcd' model parameters

\begin{tabular}{|c|c|c|c|c|}
\hline & a & b & c & d \\
\hline Kolhiki & 0.97 & 902.04 & 0.66 & 0.00 \\
\hline Triantafillia & 0.35 & 700.00 & 0.00 & 0.10 \\
\hline Parorio & 0.55 & 650.00 & 0.40 & 0.00 \\
\hline Papadia Skopos & 0.80 & 500.00 & 0.40 & 0.00 \\
\hline
\end{tabular}

Indicative results regarding the hydrologic simulation on a catchment scale are shown in Fig. 4. The figure depicts the estimated monthly runoffs $(\mathrm{mm})$ of the basin up to Kolhiki reservoir for the ten year period of initial simulation, showing that a slight reduction (i.e., negative trend) on the monthly runoffs occurs during this period.

The operation of each reservoir is described by the water balance equation (1). In this approach, the initial simulation is performed using the runoff estimations of the ten year period, given the current water requirements in the region. Fig. 5 contains four representative graphs, one for each reservoir, with the monthly variation of the net water supply stored in the reservoir, as well as, the corresponding failures recorded during the same period.

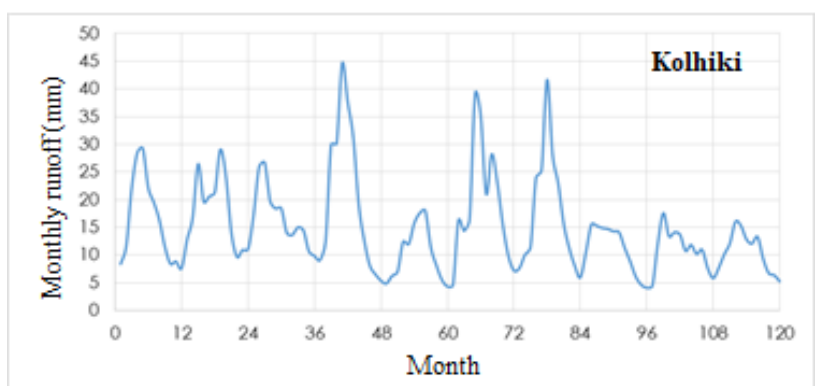

Figure 4. Monthly runoff as estimated using the 'abcd' model 

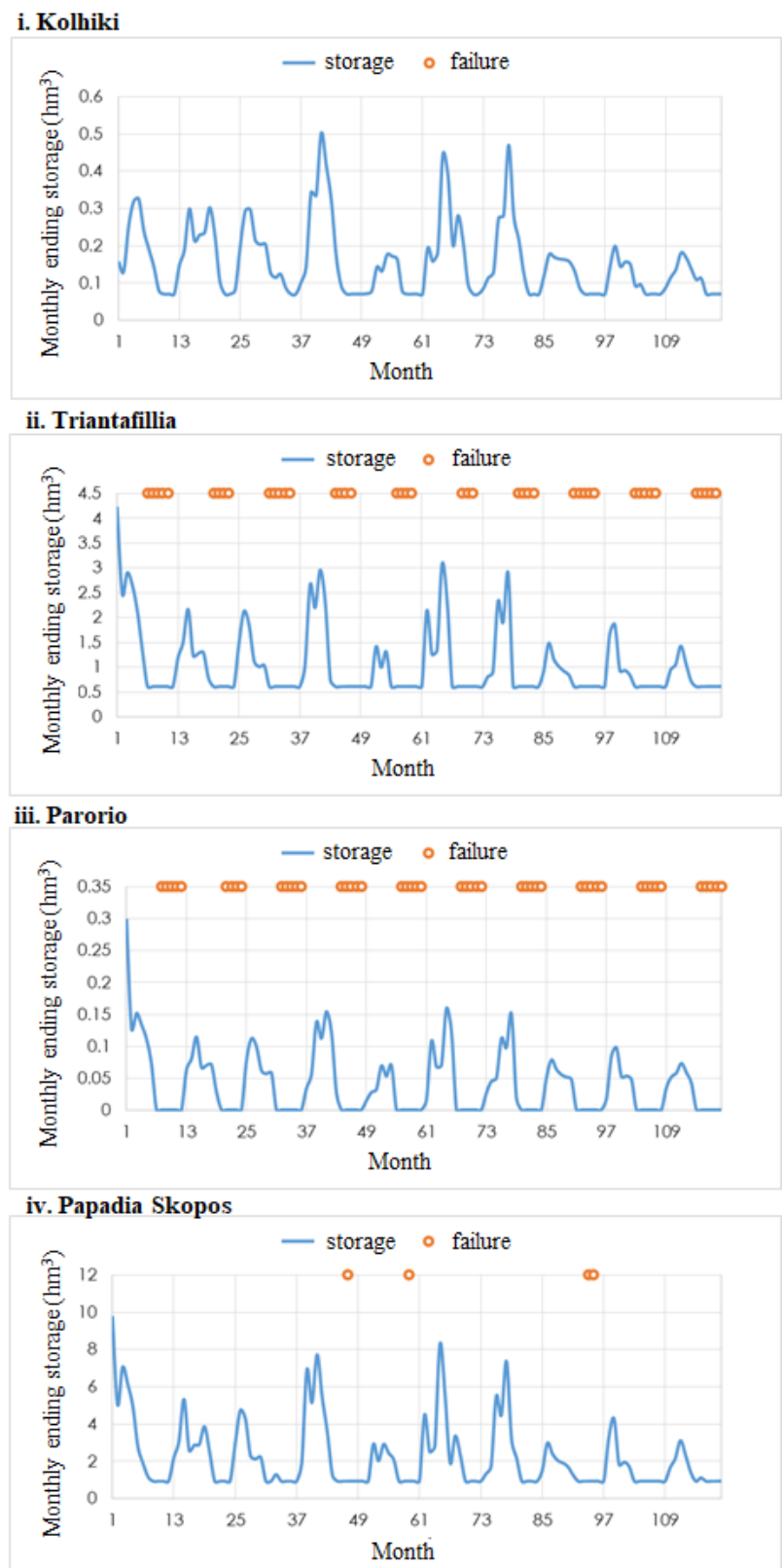

Figure 5. Initial reservoirs' simulation

The aforementioned figure illustrates the current state of each reservoir, regarding any systematic incapability to meet water requirements during the peak period (i.e., mainly summer months), as a function of the current practices of irrigation water supply distribution. As shown, failures are observed mainly in the reservoirs of Triantafillia and Parorio, while the initial operation for Kolhiki does not indicate any failure in meeting water requirements.

Further model simulation is conducted with the aim of implementing the scenarios described in Section 3, which were performed in order to compare current WRM practices (i.e., the zero scenario) with other WRM plans and under changing climatic conditions. For demonstration purposes, results regarding each one of the 16 scenarios are summarized in Table 3. Reliability values regarding the scenarios that involve population growth are not shown in this table for the reservoirs that do not supply urban water, according to the current WRM practices.

Overall, the implementation of the scenarios shows the inadequacy of the existing hydrosystem to fully satisfy irrigation requirements during summer months. The fact that the largest proportion of irrigated land depends on the Triantafillia Reservoir (the one of highest volume) does not provide flexibility with regard to the redistribution of the quantities of water available for irrigation per reservoir. Specifically, with respect to zero scenario (A), any alteration in irrigation water supply (scenarios C) can only be combined with a reduction in the irrigation demand that finally results in a satisfactory reduction in the percentage of failures. Since a target of reliability at around $90 \%$ is considered satisfactory for irrigation, PapadiaSkopos Reservoir is found to be able to meet irrigation needs of greater area extent, compared to the current (from 9 to $12 \mathrm{~km}^{2}$ ) without a need to affect the quantity of water for irrigation purposes. Also, if the irrigation demand is reduced, it is achievable to double the water supply with a reliability of slightly less than $90 \%$, a fact that also contributes to the reservoir's reliability increase, however, as this is a multipurpose reservoir, the irrigation demand has not changed for scenario D. For Parorio Reservoir, which presents the lowest reliability, estimates are given with caution as the available data on its technical and operation characteristics are limited. Indicatively, a reduction in monthly failures of about $10 \%$ can only be achieved by combining lower irrigation demand and by supplying only the $50 \%$ of the irrigated areas for which the dam is designed to operate. Kolhiki Reservoir, which operates supplementary to the Triantafillia, can meet the irrigation requirements for approximately $2.5 \mathrm{~km}^{2}$ (according to the zero scenario, it irrigates $1 \mathrm{~km}^{2}$ ), while the percentage of failures remains at the desired levels (up to about $10 \%$ ). Indicative is the fact that the slight decrease in the total amount of irrigation water required per year results in a significant reduction in failures (e.g., when needs are set at $240 \mathrm{~mm}$ from the 288 $\mathrm{mm}$ for which they are designed, the failures are about half). To achieve a failure rate of less than $27 \%$ and for the same irrigated area, the average demand for irrigation purposes should be decreased significantly to $200 \mathrm{~mm}$ per year, as there is no flexibility to further reduce the irrigated area supplied by this reservoir, due to the much smaller capacity of the other reservoirs. 
Regarding the application of the CC scenarios, as expected, the mild one $\left(\mathrm{B}_{1}\right)$ systematically leads to a reduction in the percentage of failures, the severe $\left(\mathrm{B}_{2}\right)$ to a significant increase and the moderate $\left(\mathrm{B}_{3}\right)$ to approximately same failure rates. As the water required to supply the population corresponds to a sufficiently small amount compared to this for irrigation, the application of the population growth scenarios (C) does not affect the reliability of the system. Correspondingly, when the population is applied in combination with each climatic, there is a slight or even no decrease in reliability. In all other combinations, namely joint population, $\mathrm{CC}$ and scenarios of change in the irrigation water supply distribution, the objective to increase the reliability of the Triantafillia and Parorio reservoirs, which exhibit the highest percentage of failures, is achieved. At the same time, the reliability of the other two reservoirs is maintained at the desired levels for irrigation purposes.

Table 3. Percentage failure to fully meet water requirements per reservoir and for each scenario

\begin{tabular}{|c|c|c|c|c|}
\hline Scenario & Kolhiki & Triantafillia & Parorio & $\begin{array}{c}\text { Papadia } \\
\text { Skopos }\end{array}$ \\
\hline A & $0.00 \%$ & $36.97 \%$ & $40.83 \%$ & $3.33 \%$ \\
\hline $\mathbf{B}_{1}$ & $0.00 \%$ & $26.74 \%$ & $31.94 \%$ & $0.00 \%$ \\
\hline $\mathbf{B}_{2}$ & $0.00 \%$ & $39.83 \%$ & $48.06 \%$ & $13.89 \%$ \\
\hline $\mathbf{B}_{3}$ & $0.00 \%$ & $35.10 \%$ & $41.94 \%$ & $4.17 \%$ \\
\hline A-C & - & $36.97 \%$ & - & $3.33 \%$ \\
\hline $\mathbf{B}_{1}-\mathbf{C}$ & - & $26.74 \%$ & - & $0.00 \%$ \\
\hline $\mathbf{B}_{2}-\mathrm{C}$ & - & $40.11 \%$ & - & $13.89 \%$ \\
\hline $\mathrm{B}_{3}-\mathrm{C}$ & - & $35.10 \%$ & - & $4.44 \%$ \\
\hline A-D & $5.00 \%$ & $27.73 \%$ & $31.67 \%$ & $10.00 \%$ \\
\hline $\mathbf{B}_{1}-\mathrm{D}$ & $0.28 \%$ & $18.38 \%$ & $13.89 \%$ & $0.00 \%$ \\
\hline $\mathbf{B}_{2}-\mathbf{D}$ & $8.06 \%$ & $27.86 \%$ & $40.00 \%$ & $21.11 \%$ \\
\hline B $_{3}-\mathbf{D}$ & $6.11 \%$ & $26.74 \%$ & $30.00 \%$ & $10.28 \%$ \\
\hline A-C-D & - & $27.73 \%$ & - & $10.00 \%$ \\
\hline B $_{1}-\mathrm{C}-\mathrm{D}$ & - & $18.38 \%$ & - & $0.00 \%$ \\
\hline B $_{2}-\mathrm{C}-\mathrm{D}$ & - & $27.86 \%$ & - & $21.39 \%$ \\
\hline$B_{3}-C-D$ & - & $27.02 \%$ & - & $10.28 \%$ \\
\hline
\end{tabular}

\section{Conclusions and recommendations}

This research work deals with an integrated assessment regarding a hydrosystem's resilience under changing conditions. The analysis is performed for a rural area in Northern Greece, named Florina, where four reservoirs operate to meet irrigation, industrial and urban water requirements. In this regard, the hydrosystem's performance under 16 scenarios is investigated and presented. The main findings are summarized as follows:

Based on the current WRM practices, the irrigation water demand is not fully met according to the initial analysis performed at a reservoir level. Indicatively for the ten year historic period, the Kolhiki and Papadia-Skopos reservoirs present the highest reliability (overall failure is about $0.3 \%$ ), while the Triantafillia and Paroriou reservoirs do not fully satisfy monthly irrigation requirements (with a percentage failure around $37 \%$ and $40.8 \%$, respectively). Various scenarios are also investigated that each of them indicates a change with respect to the current WRM state. An updated plan regarding irrigation water supply distribution is examined, as well as, the possible impact on the hydrosystem using three $\mathrm{CC}$ scenarios for the period 2020-2050, combined or not with a population growth scenario. Overall, the implementation of 16 scenarios, including zero, has shown the inadequacy of the existing hydrosystem to completely meet irrigation requirements during summer months. This analysis for Florina region reveals the limited resilience of the existing system regarding current requirements met and weakness in adaptation under various $\mathrm{CC}$ and population growth scenarios. The preliminary evaluation initially indicates the necessity for a system enhancement, in terms of designing new WRM projects. Finally, the lack of an integrated monitoring network for the hydrological and meteorological parameters leads to additional uncertainty in the estimates presented. The installation of such a network in the long run will lead to the acquisition of representative data that will contribute to a more accurate hydrological simulation of the area.

Future research is needed to explore the adoption of a probabilistic approach for the hydrosystem's simulation by using a suitable stochastic model for the timeseries generation. It is crucial, as it will incorporate some aspects of random variation to the system. As without a solid base of deterministic data it is unlikely to deliver precision in predictions, this research work is a point of departure for further analysis including a probabilistic approach to actually validate the accuracy of estimates.

Acknowledgements: We acknowledge the E-OBS dataset from the EU-FP6 project UERRA (http://www.uerra.eu) and the Copernicus Climate Change Service, and the data providers in the ECA\&D project (https://www.ecad.eu). We also acknowledge the World Climate Research Programme's Working Group on Regional Climate, and the Working Group on Coupled Modelling, former coordinating body of CORDEX and responsible panel for CMIP5. We also thank the climate modelling groups and the Data Extraction Application for Regional Climate (DEAR-Clima; http://meteo3.geo.auth.gr:3838/) for producing and making available their model output. We finally acknowledge the Earth System Grid Federation infrastructure an international effort led by the U.S. 
Department of Energy's Program for Climate Model Diagnosis and Intercomparison, the European Network for Earth System Modelling and other partners in the Global Organisation for Earth System Science Portals (GO-ESSP). Part of this analysis is financially supported by the program "Integrated water resources management in the Municipality of Florina, under the operation of the new reservoirs in the area", funded by the Municipality of Florina.

\section{References:}

[1] Biswas, A. K., 2004. Integrated water resources management: a reassessment: a water forum contribution, Water international 29.2: 248256.

[2] Bournas, A., Feloni, E. and Baltas, E., 2017. Hydrological and geomorphological analysis in the Municipality of Florina, Proceedings of the Sixth International Conference on Environment, Engineering, Planning \& Economics, Thessaloniki, Greece, June 25-30, 2017, ISBN: 978-618-5271-15-2, pp. 366-376.

[3] Thomas Jr, H.A., 1981. Improved Methods for National Water Assessment - Water Resources Contract: WR15249270, US Water Resources Council: Washington, DC, USA.

[4] Thomas, H.A., Marin, C.M., Brown, M.J. and Fiering, M.B., 1983. Methodology for water resource assessment, report to US Geological Survey. Rep. NTIS, pp.84-124163.

[5] Cornes, R.C., van der Schrier, G., van den Besselaar, E.J. and Jones, P.D., 2018. An ensemble version of the $\mathrm{E}$ OBS temperature and precipitation data sets, Journal of Geophysical Research: Atmospheres, 123(17), pp.9391-9409.

[6] Haylock, M.R., Hofstra, N., Klein Tank, A.M.G., Klok, E.J., Jones, P.D. and New, M., 2008. A European daily high resolution gridded data set of surface temperature and precipitation for 1950-2006, Journal of Geophysical Research: Atmospheres, 113(D20).

[7] Gutowski Jr, W.J., 2009. Coordinated Regional Downscaling Experiment (CORDEX), In AGU Fall Meeting Abstracts.

[8] Marinou, P.G., Feloni, E.G., Tzoraki, O. and Baltas, E.A., 2017. An implementation of a water balance model in the Evrotas basin, Eur. Water, 57, pp.147-154.

[9] Mimikou, M. and Baltas, E., 1996. Climate change impacts on the reliability of hydroelectric energy production, Hydrological Sciences Journal, 42, pp. 661-678.

[10] Baltas, E. A., and Mimikou, M. A., 2005. Climate change impacts on the water supply of Thessaloniki, International Journal of Water Resources Development, 21(2), 341-353. 